\title{
Impact of different feeding systems on cost-effectiveness and Eimeria spp. infections in Canarian goat kids
}

\author{
Alexandr Torres $^{\mathrm{a}, *}$, Juan Capote ${ }^{\mathrm{a}}$, María Fresno ${ }^{\mathrm{a}}$, Alejandra Eguiza ${ }^{\mathrm{b}}$, Emilio Barba ${ }^{\mathrm{c}}$, \\ José Manuel Molina ${ }^{c}$, Antonio Ruiz ${ }^{c}$ \\ ${ }^{\text {a } U n i t ~ o f ~ A n i m a l ~ P r o d u c t i o n, ~ P a s t u r e, ~ a n d ~ F o r a g e ~ i n ~ A r i d ~ a n d ~ S u b t r o p i c a l ~ A r e a s, ~ C a n a r y ~ I s l a n d s ~ I n s t i t u t e ~ f o r ~ A g r i c u l t u r a l ~ R e s e a r c h, ~ 38200, ~ L a ~ L a g u n a, ~ S p a i n ~}$ \\ ${ }^{\mathrm{b}}$ College of Veterinary Medicine, National Autonomous University of Mexico, 04510, Mexico City, Mexico \\ ${ }^{\mathrm{c}}$ Department of Animal Pathology, Parasitology Section, Faculty of Veterinary Medicine, University of Las Palmas de Gran Canaria, 35413, Arucas, Spain
}

\section{A R T I C L E I N F O}

\section{Keywords:}

Economic performance

Eimeria infection

Goat kid growth

Rearing system

\begin{abstract}
A B S T R A C T
Rearing strategies are key factors in the overall success of goat enterprises. In order to investigate the cost-benefit ratio of alternative methods for rearing and the impact on the course of Eimeria infections, 36 Canarian goat kids were subjected to three different regimes under field conditions. Two groups of animals were naturally reared with their mothers, feeding goat milk until weaning at 6 (Early weaning, EW) and 9 weeks of age (Traditional weaning, TW). In the remaining group, goat kids were artificially reared with a milk replacer until 9 weeks of age (Artificial feeding, AF). Coprological analysis were performed weekly to determine Eimeria oocyst shedding and, with the same frequency, changes in body weights and faecal consistency were recorded. Goat kids from group TW showed the best growth rate, while growth performance of groups EW and AF were statistical similar. Besides, compared to group TW, EW and AF management practices resulted in an overall increase of about $40 \%$ and more than $100 \%$ of the total number of oocysts excreted until the end of the experiment (week 15), respectively. Although the three experimental groups were infected with the same Eimeria species, differences in their oocysts excretion kinetics, including those of most pathogenic species, were observed throughout the experiment, indicating that the type of rearing may affect the outcome of underlying coccidiosis in the farm. Finally, the economic analysis determined that, mainly conditioned by the market price of goat milk, total operating costs per goat kid from groups EW (56.37 €) and AF (48.63€) systems were considerably lower than those obtained in group TW $(96.32 €)$. The selection of the former two rearing systems should be conditioned though to the use of management strategies preventing coccidiosis outbreaks.
\end{abstract}

\section{Introduction}

In the Canary Islands and some Mediterranean regions, goat kids are traditionally reared with their dams, and later they are weaned at around 9 weeks of life. Although this practice promotes an optimal growth and reduces weaning shock, it decreases the availability of milk for cheese production, and may lead to economic losses ( $\mathrm{Lu}$ and Potchoiba, 1988; Argüello et al., 2005). Thus, it has been reported that early weaning at 4 and 6 weeks increases the marketable quantity of milk without causing a negative impact on the growth of goat kids, which provides important benefits to the farm (Gökdal et al., 2017; Panzuti et al., 2018). Nevertheless, abrupt early weaning may cause growth retardation and weight loss, because the maturation of the digestive system is still incomplete (Magistrelli et al., 2013). On the other hand, artificial rearing during the first weeks of life can result in good daily weight gain, and is of particular interest in disease eradication and control programs (Morales-delaNuez et al., 2011). However, despite the fact that several automatic feeding systems are commercially available (Bimczok et al., 2005) and milk replacer is markedly cheaper than goat milk, many small and medium farmers are reluctant to its use because, in their opinion, this type of rearing involves greater labor cost (Argüello et al., 2005).

Infections produced by Eimeria spp. are one of the most important parasitic diseases in goat production systems worldwide (Chartier and Paraud, 2012), mainly in arid and semi-arid areas (Ruiz et al., 2006; Cavalcante et al., 2012). Although $100 \%$ of the animals of a herd may be infected by the parasite, clinical disease is mainly reported in young animals (Ruiz et al., 2006; Keeton and Navarre, 2018), while adults are

\footnotetext{
* Corresponding author at: Canary Islands Institute for Agricultural Research, P.O. box 60, 38200, La Laguna, Tenerife, Spain.

E-mail address: atorresk@icia.es (A. Torres).
} 
usually asymptomatic carriers due to development of immunity (Dai et al., 2006; Ruiz et al., 2013a). Clinical signs associated to coccidiosis by Eimeria spp. include dehydration, anorexia, weight loss, weakness and recumbency. Coccidiosis is also accompanied by diarrhea varying in severity from yellowish to brownish faeces of different consistency, sometimes watery faeces containing blood and small pieces of the intestinal mucosa (Ruiz et al., 2013a, b; Ruiz et al., 2014).

Monospecific Eimeria infections in goats are uncommon in field conditions, where the rule is that, irrespectively of the age, animals are infected by two, three or even more different Eimeria spp. (Balicka-Ramisz et al., 2012; Zhao et al., 2012). Four species are known to be highly pathogenic and most times they are the most prevalent, namely E. ninakohlyakimovae, E. arloingi, E. christenseni and E. caprina (Hashemnia et al., 2012; Andrews, 2013). In goat kids, coccidiosis may be a problem from the third or fourth week of life onwards and, particularly, during weaning due to stress caused by changes on feeding diets, separation from their dams, location into different pens, etc. (Ruiz et al., 2006). This leads to important economic losses, which are derived from deaths, delayed growth rate, treatments and veterinary assistance (Fthenakis and Papadopoulos, 2018; Windsor et al., 2018).

The aim of the present study was to assess the cost benefit associated with the application of three management strategies of rearing goat kids and to evaluate the impact on the course of Eimeria infections in field conditions.

\section{Materials and methods}

\subsection{Experimental animals}

The trial was a reference-controlled field study with parallel groups and was carried out in the facilities of the experimental farm of the Instituto Canario de Investigaciones Agrarias in Tenerife (Spain). Thirtysix Canarian goat kids from birth to 15 weeks of age were included in this study. Goat kids were divided into three balanced groups $(n=12,6$ males and 6 females) allocated in separated pens. Traditional weaning group (TW) included animals that were kept with their dams from birth until weaning at 9 weeks of age. Commercial starter concentrate (Grupo Capisa, Spain), alfalfa and water were provided as of 2 weeks of age. In Early weaning group (EW), animals were kept with their dams from birth, as in TW group, but weaning took place at 6 weeks of age. Earlyweaning concentrate (Cereales Archipiélago, Spain), alfalfa and water were also provided as of 2 weeks of age. After weaning and until 9 weeks of age, goat kids were fed with a controlled level of early-weaning concentrate (500 g/d/kid) and alfalfa. In Artificial feeding group (AF), goat kids remained with their dams for 2 days to receive colostrum. Thereafter, they received ad libitum milk replacer (Bacilactol ${ }^{\circledR}$, Grupo Capisa, Spain) reconstituted at $16 \% \mathrm{w} / \mathrm{w}$ using an automated feeding system until weaned ( 9 weeks of age). Similar to TW group, goat kids were previously exposed to commercial starter concentrate, alfalfa and water. From week 9 onwards, all the animals were exclusively fed with commercial starter concentrate $(1000 \mathrm{~g} / \mathrm{d} / \mathrm{kid})$ and alfalfa. The main composition of the feed is shown in Table 1 . Body weight of each goat kid (BW) was recorded weekly and faecal samples were weekly collected from the rectum from 5 to 15 weeks of age. All animals were treated with $2 \mathrm{mg} / \mathrm{kg}$ BW p. o. of diclazuril (Rumicox ${ }^{\circledR}$, Esteve Veterinaria) at week

Table 1

Composition of the feeds.

\begin{tabular}{llll}
\hline & $\begin{array}{l}\text { Starter } \\
\text { concentrate }\end{array}$ & $\begin{array}{l}\text { Early-weaning } \\
\text { concentrate }\end{array}$ & $\begin{array}{l}\text { Milk } \\
\text { replacer }\end{array}$ \\
\hline $\begin{array}{c}\text { Crude protein } \\
\text { (\%) }\end{array}$ & 17.0 & 17.0 & 23.0 \\
Crude fat (\%) & 3.4 & 2.5 & 23.0 \\
Crude fibre (\%) & 6.0 & 4.2 & 0.0 \\
Crude ash (\%) & 6.1 & 6.0 & 8.2 \\
\hline
\end{tabular}

10 of the experiment. Animal procedures were conducted in strict accordance with national ethics, the current European Animal Welfare Legislation (ART13TFEU) and by institutional review board-approved protocols.

\subsection{Clinical and parasitological determinations}

The amount of oocysts per gram of faeces (OPG) was determined using a modified McMaster technique (Thienpont et al., 1979). Dilutions of the faecal suspension by 10 or 100 times were done to enable counting when the number of oocysts was very high. The faecal consistency (FS) was scored immediately after individual collection according to keys described previously (Ruiz et al., 2014). Signs of diarrhoea were judged as evident when FS was $>0$ or when faeces of lower consistency were observed down legs, including explosive, fluid and watery diarrhoea.

Every sampling week, faecal samples from animals of each group were also pooled for the identification of the different Eimeria species. For this purpose, faecal cultures were performed in $2 \%$ potassium dichromate at room temperature $\left(20-25^{\circ} \mathrm{C}\right)$ for at least one week in Petri culture-dishes to allow sporulation. Oocysts were then concentrated by flotation in saturated sodium chloride, washed with distilled water, centrifuged at $1500 \mathrm{x} \mathrm{g}$ for $10 \mathrm{~min}$ and preserved at $4{ }^{\circ} \mathrm{C}$ until the analysis was performed. The identification was carried out under a $40 \mathrm{X}$ objective using a calibrated eyepiece according to keys reported previously (Levine and Ivens, 1986; Alyousif et al., 1992; Soe and Pomroy, 1992).

\subsection{Economic analysis}

In order to compare the costs among the three management strategies, the feed efficiency ratio of goat milk (FER, intake/gain) in goat kids of the same experimental farm was calculated at 6 and 9 weeks. Thus, the milk suckled by animals weaned at early stage and those reared under traditional model could be estimated, and the corresponding outcome could be considered as marketable milk. For this purpose, 14 goat kids ( 7 males and 7 females) were fed three times a day $(0800,1300$ and $1800 \mathrm{~h}$ ) during 9 weeks by using bucket feeders fitted with nipples. Milk consumption was recorded daily and goat kids were weighted weekly. The FER of goat milk obtained were $7.71 \mathrm{~L} / \mathrm{kg}$ and $9.81 \mathrm{~L} / \mathrm{kg}$ at 6 and 9 weeks, respectively. In Canary Islands, the average milk price in 2019, including subsidies, was $0.82 € / \mathrm{L}$ (BOC, 2019; FEGA, 2020). Prices paid for milk replacer and early-weaning concentrate were 2.60 and $1.40 € / \mathrm{kg}$, respectively. Labor expenses for each rearing management were estimated according to Delgado-Pertínez et al. (2009a) and considered a work wage of $10.0 € / \mathrm{h}$. Other artificial feeding costs were also taken into account, such as depreciation and maintenance for the automatic feeder, water and electricity consumption. Calculations were made per goat kid from birth until 9 weeks of life.

\subsection{Statistical analysis}

Information on the growth pattern helps to determine the efficacy of feeding and breeding strategies (Lambe et al., 2006). Growth curve parameters were estimated according to the Gompertz equation:

$\mathrm{f}(\mathrm{x})=\mathrm{W}_{\mathrm{f}} \exp \left\{[1-\exp (-\mathrm{bx})] \ln \left(\mathrm{W}_{\mathrm{f}} / \mathrm{W}_{0}\right)\right\}$

where $f(x)$ was BW at age $x, W_{0}$ and $W_{f}$ were the zero- and infinite-time values of BW, respectively, and b was constant (Porter et al., 2010). BW and age were given in kilograms and weeks, respectively. Calculations were carried out with non-linear regression option. From these parameters, time of inflection (timeI), BW at inflection (BWI) and the growth rate per day at inflection (GRI.day) were calculated according to Porter et al. (2010).

Faecal oocyst counts were transformed into the logarithm of OPG plus one $(\log [\mathrm{OPG}+1])$ to obtain normal distributions (Kolmogorov- 
Smirnov's Normality Test). Comparison of OPG counts among the three management strategies was performed by One Way Repeated Measures Analysis of Variance. For all pairwise multiple comparison procedures the Holm-Sidak method was used, while Krustal-Wallis test was employed for faecal score analysis. The average faecal consistency score per animal and the average of log $(\mathrm{OPG}+1)$ per animal were calculated and then compared among the three groups by one-way ANOVA with pairwise post-hoc comparisons by the Tukey test.

The Pearson correlation test was used for the analysis of the association between parasitological and productive parameters (BW) at all sampling times (weeks 5-15). Additionally, total weight gains from week 5 of life up to the end of the study for each kid was calculated and Pearson correlations between this parameter and the average OPG and FS were determined, both for each experimental group and for all three groups together. Finally, peak OPG values of goat kids from groups TW, EW and AF were correlated with weight gain at each week following OPG peaks and with total weight gain between the week were peak OPG values were found and the end of the study.

Analysis were carried out by the statistical software SigmaPlot 12.0 and the differences were considered significant at $P<0.05$.

\section{Results}

\subsection{Growth performance}

Growth curves and their functional parameters according to Gompertz equation are presented in Fig. 1 and Table 2, respectively. In order to get the highest goodness of fit criteria for the Gompertz model used, $\mathrm{W}_{0}$ was not restricted when modeling the growth data of the different feeding and weaning treatments. The parameter that described the mature $\mathrm{BW}\left(\mathrm{W}_{\mathrm{f}}\right)$ of the goat kids was significantly different, with group TW showing a higher value than the other two groups. However, the constant $b$, which determines the growth rate in the Gompertz equation was not different among treatments $(P>0.05)$. As shown by Table 2 , the estimated $\mathrm{W}_{\mathrm{f}}$ values varied between 21.94 and $29.75 \mathrm{~kg}$. In addition, significant differences for BWI among managements were observed, ranging between 8.08 and $10.95 \mathrm{~kg}$, but there were not statistical differences for GRI.day. Furthermore, all groups attained inflection at 6-7 wk.

\subsection{Clinical and parasitological findings}

Mean values and statistical differences of FS recorded from the animals of the three experimental groups are depicted in Fig. 2. The analysis of the results shows that the highest mean FS values were observed in

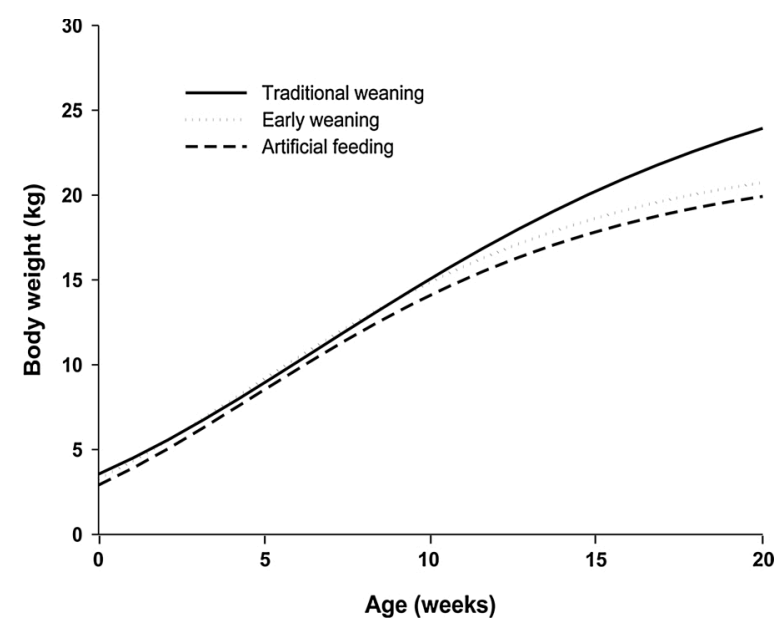

Fig. 1. Growth curves of goat kids reared under three different management strategies. The lines indicate fitted values based on the Gompertz equation.
Table 2

Growth parameters in goat kids reared under three different management strategies corresponding to Gompertz equation.

\begin{tabular}{llllll}
\hline & $\begin{array}{l}\text { Traditional } \\
\text { weaning }\end{array}$ & $\begin{array}{l}\text { Early } \\
\text { weaning }\end{array}$ & $\begin{array}{l}\text { Artificial } \\
\text { feeding }\end{array}$ & SEM & $\begin{array}{l}P \text { - } \\
\text { value }\end{array}$ \\
\hline $\mathrm{W}_{\mathrm{f}}(\mathrm{kg})$ & $29.75^{\mathrm{b}}$ & $22.75^{\mathrm{a}}$ & $21.94^{\mathrm{a}}$ & 1.357 & 0.031 \\
$\mathrm{~b}\left(\mathrm{wk}^{-1}\right)$ & 0.12 & 0.16 & 0.16 & 0.010 & 0.169 \\
timeI $(\mathrm{wk})$ & 6.50 & 5.25 & 5.50 & 0.420 & 0.451 \\
BWI $(\mathrm{kg})$ & $10.95^{\mathrm{b}}$ & $8.37^{\mathrm{a}}$ & $8.08^{\mathrm{a}}$ & 0.499 & 0.031 \\
$\begin{array}{c}\text { GRI.day } \\
\quad(\mathrm{g} / \mathrm{d})\end{array}$ & 182.37 & 157.69 & 175.14 & 5.523 & 0.174 \\
R-Square & 0.991 & 0.962 & 0.965 & & \\
\hline
\end{tabular}

${ }^{\mathrm{a}-\mathrm{b}}$ Means without a common superscript letter within the same row are different $(P<0.05)$ by using Turkey test.

${ }^{1} \mathrm{~W}_{0}$ and $\mathrm{W}_{\mathrm{f}}$ are the zero- and infinite-time values of $\mathrm{BW}$, respectively, $\mathrm{b}$ is constant, timeI is time of inflection, BWI is BW at inflection time and GRI.day is the growth rate per day at inflection time.

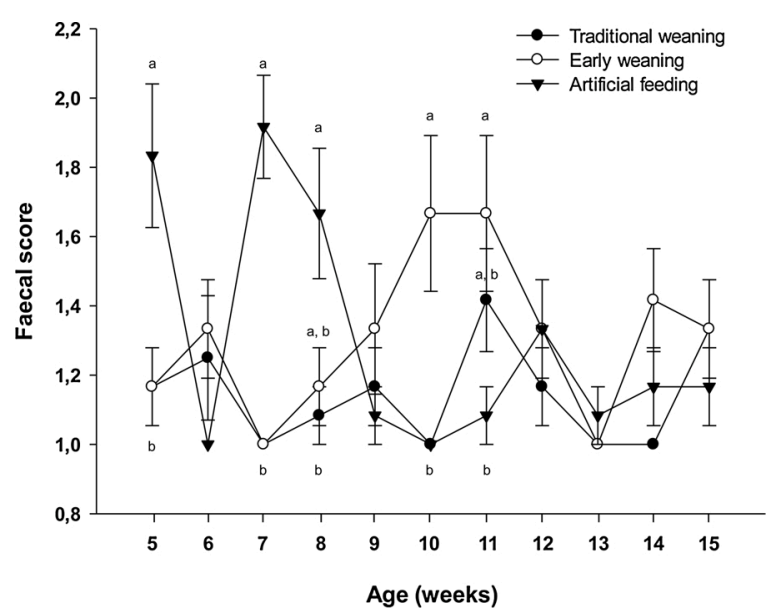

Fig. 2. Faecal consistency in the different experimental groups. The following criteria were established: 1) normal formed faeces; 2) unformed faeces of light reduced consistency; 3) faeces of moderate reduced consistency; 4) yellowish, greenish or brownish liquid faeces; 5) liquid faeces of reddish colour and/or presence of mucosa pieces. Data are expressed as means \pm SEM. ${ }^{a-b}$ Means without a common superscript letter at the same week are different $(P<0.05)$ by using Holm-Sidak test.

animals from AF group during weeks 5 and 7 (FS > 1.8), however, this value did not remain consistent and showed fluctuations. On the other hand, the animals from EW group showed a reduction in faecal consistency with FS values close to 1.6 in a later period (weeks 10-11), while goat kids from TW group showed a lower mean FS value throughout the experiment compared to the other two groups, with a slight increase at week 11. The comparative analysis of the average faecal consistency score per animal showed significant differences between groups, especially relevant when comparing TW and FA groups.

Mean OPG values of the three experimental groups throughout the study has been depicted in Fig. 3. As for the faecal consistency score, the average of $\log (\mathrm{OPG}+1)$ per animal were calculated and then compared among management strategies, the results showing significant differences between the three groups, particularly when comparing EW and AF groups. In the course of the study, TW group showed peak values at week 7th of life and, in general, had lower mean OPG counts when compared with the other two experimental groups. This difference was more evident when comparisons were performed on cumulative counts at the end of the experiment (data not shown). The kinetics of faecal oocyst counts was different in EW and AF groups compared to TW group, with peak values at week 9. OPG values were significantly higher in AF group with respect groups TW and EW $(P<0.001)$ at this time point. Actually, faecal counts of several animals artificially fed were extremely 


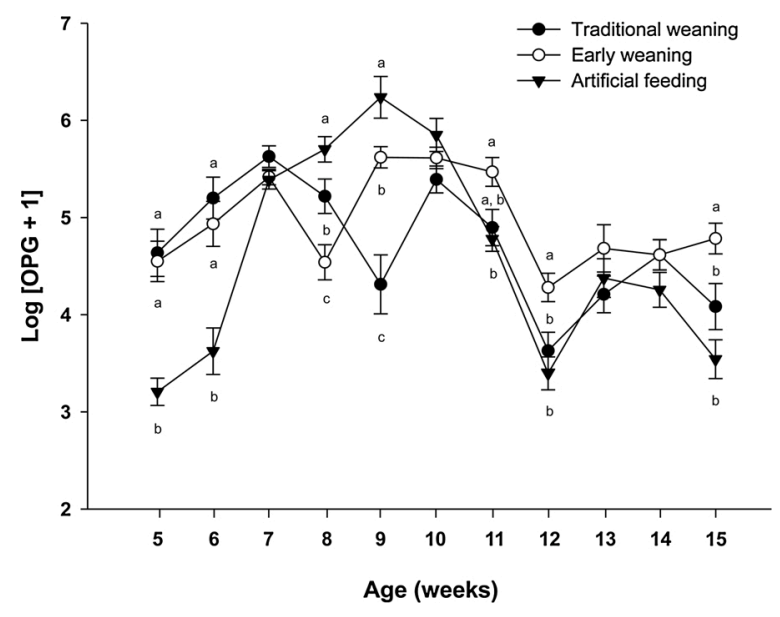

Fig. 3. Fluctuation of Eimeria oocyst counts in goat kids reared under three different management strategies. The data are expressed as transformed Log values $(O P G+1)$ and averages \pm SEM are represented. ${ }^{\mathrm{a}-c}$ Means without a common superscript letter at the same week are different $(P<0.05)$ by using Holm-Sidak test.

high at this week, with values reaching almost 8 million OPG, despite these animals showed significantly lower mean OPG values at the beginning of the study $(P<0.001)$ compared with the other two groups. The EW group, after reaching peak values at week 9th of life, showed higher mean oocyst counts than the other two experimental groups, reaching statistical significance at weeks 11,12 and 15 of the study $(P<$ 0.05 to $P<0.001$ ). Interestingly, relatively high oocyst counts were recorded after treatment with diclazuril at week 10, which was particularly evident in group EW.

Changes in OPG counts were positively associated to faecal score, particularly in EW group (Fig. 2 and 3), while peak values for faecal scores in group AF (highest score between weeks 7 and 8 of life) preceded the increased in faecal oocyst counts (weeks 8-10). Nevertheless, no statistical significance could be demonstrated between both parameters in any of the three management strategies.

According to higher OPG counts and transient increased values of faecal scores observed in groups EW and AF, goat kids from both groups showed decreased BWs as depicted in Fig. 1. Nevertheless, the statistical analysis revealed a lack of correlations among these parameters in both EW $\left(-0.027 ; \mathrm{R}^{2}=7.45 \times 10^{-4} ; P=0.758\right)$ and $\mathrm{AF}\left(-0.008 ; \mathrm{R}^{2}=5.89 \times\right.$ $\left.10^{-5} ; P=0.929\right)$ groups. Surprisingly, significant negative correlations between faecal oocyst counts and BW could only be demonstrated in group TW $\left(-0.349 ; \mathrm{R}^{2}=0.121 ; P<0.01\right)$. Differences in weight gain were detected at the two time points after the peak of oocyst shedding (week 9), at which points higher OPG counts were associated with lower weight gains $(P<0.05)$.

Overall, the Eimeria species most frequently found in the three experimental groups were E. christenseni (around $40 \%$ ), followed by E. arloingi (25-30 \%) and E. ninakohlyakimovae (10-15\%); other minor species (grouped as "other species") included E. alijevi, E. caprina, E. caprovina, E. jolchijevi, E. hirci, E. aspheronica, which were all individually recorded in a percentage lower than $10 \%$ (Table 3). However, differences in their kinetics over the course of the experiment were found. Thus, the percentage of $E$. arloingi and E. ninakohyakimovae were high at the beginning of the sampling period (weeks 5-6 of life) in group TW, remained relatively low up to week 13 and showed an additional increase at weeks 14 and 15; while just the opposite was recorded for E. christenseni. Approximately the same picture was found in group EW but, in this case, increased frequency for E. ninakohlyakimovae was extended up to week 7 and a further increase for E. arloingi was found between weeks 9 and 10. During this period, when the percentage of these two species was higher, an increase in the FS values was also observed. The recording of data for goat kids reared under AF also

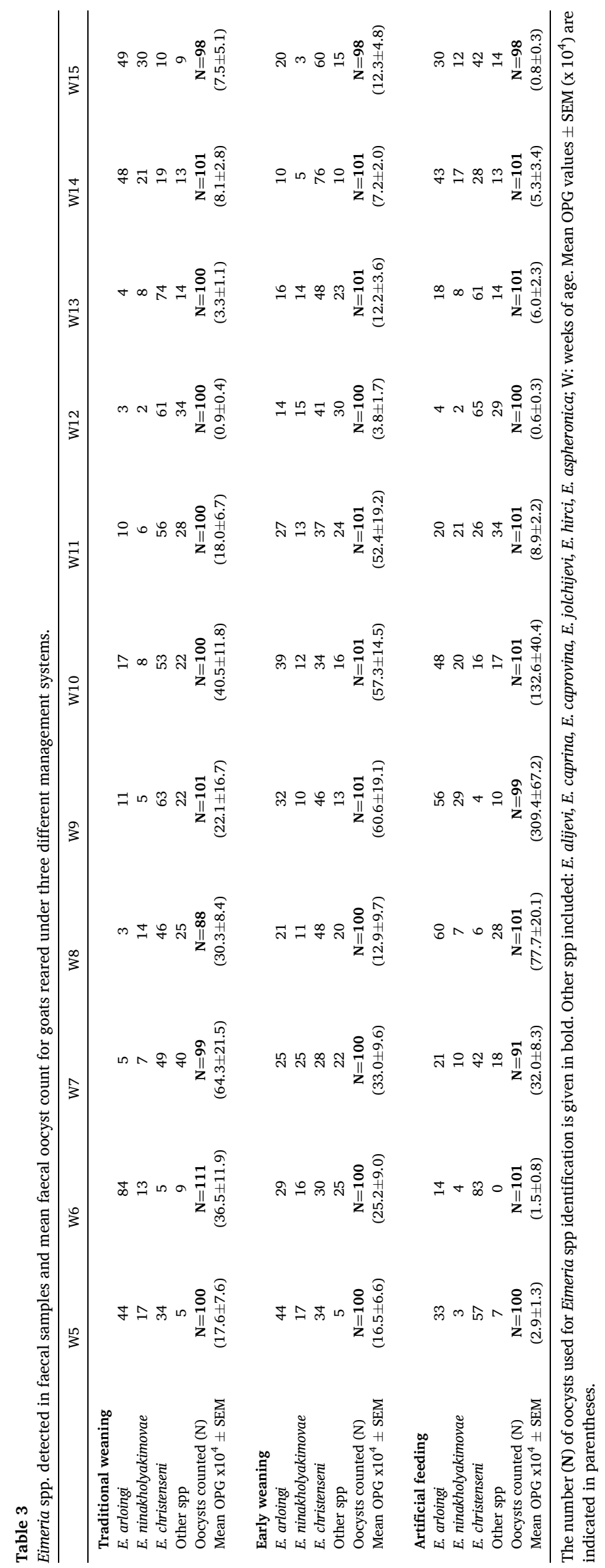


revealed that peak values for the most pathogenic Eimeria species (E. ninakohlyakimovae and E. arloingi) were found between week 8 and 11 , coinciding with highest values for OPG counts but, in this occasion, the reduction of faecal consistency (higher FS) was observed earlier.

After treatment with diclazuril (week 10), an increase in the percentages of $E$. arloingi and E. ninakohlyakimove was found three weeks later in groups TW and AF. In contrast to the previous two groups, E. christenseni was the most abundant species during the whole period examined after treatment in group EW.

\subsection{Economic efficiency}

Feeding costs for the three management strategies are given in Table 4. Total operating costs per goat kid of group TW (96.32 $€$ ) were considerably higher than in EW (56.37 €) and AF (48.63 €) systems. These differences would be mainly determined by the market price of goat milk, early-weaning concentrate and milk replacer. Therefore, weaning at 6 weeks of age and artificial feeding reduced feeding costs by around $40 \%$ and $50 \%$ compared to weaning at 9 weeks, respectively. In addition, early-weaned goat kids do not seem to generate an important extra labor respect to the traditional weaning. Nevertheless, goat kids artificially reared using an automated feeding system required almost twice more labor expense than those reared under natural suckling systems.

\section{Discussion}

\subsection{Growth performance}

The estimated $\mathrm{W}_{\mathrm{f}}$ values obtained in the present experiment were lower than the real Canarian goat adult weight, referenced by Castro et al. (2017) at 45 and $70 \mathrm{~kg}$ for females and males, respectively. It has been reported that Gompertz model can underestimate the asymptote constant in goats, especially when the kid's weighing age is limited to less of 4 months of life (Najari et al., 2007). Besides, it is important to emphasize that the performance of Gompertz equation or any other growth models may be constrained by short-term variations that are less influent in long-term growth as noted by Rocha et al. (2015). Moreover, the literature reports a wide range for timeI and BWI for different goat breeds, and even for the same breed. Thus, for example, Gaddour and Najari (2008) and Kume and Hajno (2010) estimated for Alpine goats a BWI of 6.08 and $9.04 \mathrm{~kg}$ at a timeI of 15.5 and 47 days, respectively. Ghiasi et al. (2018) noted that such differences in growth parameters may be explained by genotype factor, data structure and management strategy. The same authors apprised that age and weight at inflection point may be used to determine the optimal slaughter age, because BW

Table 4

Feeding costs per goat kid reared under three different management strategies. ${ }^{1}$

\begin{tabular}{|c|c|c|c|}
\hline & $\begin{array}{l}\text { Traditional } \\
\text { weaning }\end{array}$ & $\begin{array}{l}\text { Early } \\
\text { weaning }\end{array}$ & $\begin{array}{l}\text { Artificial } \\
\text { feeding }\end{array}$ \\
\hline $\begin{array}{l}\text { Marketable milk consumed } \\
\text { (L) }\end{array}$ & 108.40 & 49.72 & - \\
\hline Suckled milk cost $(€)$ & 88.89 & 40.77 & - \\
\hline $\begin{array}{l}\text { Early-weaning concentrate } \\
\text { consumed (kg) }\end{array}$ & - & 5.46 & - \\
\hline $\begin{array}{l}\text { Early-weaning concentrate } \\
\text { cost }(€)\end{array}$ & - & 7.65 & - \\
\hline Milk replacer consumed (kg) & - & - & 11.54 \\
\hline Milk replacer cost $(€)$ & - & - & 30.00 \\
\hline Total feed costs $(€)$ & 88.89 & 48.42 & 30.00 \\
\hline Labor expense $(€)$ & 7.43 & 7.95 & 14.63 \\
\hline $\begin{array}{l}\text { Other artificial feeding costs } \\
(€)\end{array}$ & - & - & 4.00 \\
\hline Total operating costs & 96.32 & 56.37 & 48.63 \\
\hline
\end{tabular}

${ }^{1}$ From birth to the 9th week of age. Other artificial feeding costs included: automated feeding system depreciation, electricity and water consumption. gain reaches its peak at this point. However by using this formula, the values estimated in this study for optimal slaughter age and weight are greater than in the real management practice, because most of the goatkeepers in Canary Islands slaughter the male kids at a very young age: 15 days and 5-6 kg live weight (Argüello et al., 2005). Therefore, if the kids are slaughtered with higher live weights, regardless of the lactation method used, there would be a significant increase in the yield of the carcasses.

The better growth performances exhibited by the goat kids belonging to group TW, in comparison with the other two groups, might be attributable not only to the intrinsic differences in nutrient composition among goat milk, milk replacer and early-weaning concentrate but also to the presence (long- or short-term) or absence of the dam with the newborn ruminant. On this way, De Paula Vieira et al. (2012) demonstrated that dairy calves reared with an older social companion increased solid feed intake preweaning and BW gains before and after weaning when compared with calves housed in groups of a similar age, due to the different feeding behavior as consequence of social learning. Thus, calves that consume little solid feed before weaning are more likely to experience poor growth and prolonged hunger after weaning until intake of solid feed meets their requirements for maintenance and growth (Costa et al., 2015). Furthermore, Abecia et al. (2014) reported differences in acetate:propionate ratio in the rumen between goat kids reared with their dams and artificially reared, suggesting that the concentrate and forage intake were lower in the animals fed on milk replacer and isolated from adult animals, despite both groups having access to the same forage and concentrate offered ad libitum.

Many authors also found a lower growth in early-weaned and/or artificially reared goat kids compared to those traditionally reared (Argüello et al., 2004; Paez Lama et al., 2013; Tsiplakou et al., 2016), highlighting that the severity of weaning shock may affect the growth rate immediately thereafter. However, others authors did not observe differences in live weight at different ages between natural and artificial rearing systems (Delgado-Pertínez et al., 2009a, b; De Palo et al., 2015). Indeed, new technology and feed additives in manufacturing milk replacers and starter feeds for calves, lambs and goat kids have improved its palatability, stability, and digestibility. On the other hand, it should be noted that groups EW and AF both had a similar growth pattern throughout the experimental period (Fig. 1). Thus, the BW of EW kids at 15 wk $(16.18 \pm 3.82 \mathrm{~kg})$ was statistically similar to that of AF kids $(17.07 \pm 1.31 \mathrm{~kg})$, but both were significantly lower than that of TW kids $(20.42 \pm 3.71 \mathrm{~kg})$. In the present study, a compensatory weight gain after weaning for groups EW and AF could not be found. However, other studies demonstrated a growth compensation in animals weaned at early stages or artificially reared, which might be achieved by increasing feeding supply and/or a more efficient use of food after weaning (Paez Lama et al., 2013; Panzuti et al., 2018). Anyway, it would be interesting for further works to determine the minimum age at which appreciable compensation can take place in Canarian goats reared under alternative weaning systems, because the resulting changes in growth rates may only have a short-time effect.

\subsection{Clinical and parasitological findings}

Goat kids get contact with Eimeria spp. short after kidding, probably by the intake of oocysts adhered to the udders of their dams and, subsequently, by the ingestion of oocysts from the contaminated environment (Hidalgo Arguiello and Cordero del Campillo, 1999). However, the susceptibility of goat kids to coccidian infections and the development of clinical sings seems to be higher from the 3 weeks of life onward, most likely because certain physiological changes in the gastrointestinal tract of the ruminant are needed to facilitate the infection and further development of the parasite, at the same time as the protection provided by the colostrum of the dam begins to be less effective (Gregory et al., 1989). This finding is in agreement with observations of vet practitioners showing that clinical signs compatible with coccidiosis are rare 
under field conditions in goat kids younger than one month; this was the reason why faecal sampling was started at 5 weeks of age. Accordingly, Matos et al. (2018) showed that, under experimental conditions, the prepatent period of primary infected goat kids at week 3 and 4 of life with E. ninakohlyakimovae was slightly longer, and their corresponding OPG peak values were delayed some days when compared to primary infected animals at week 5 . In the same way, younger goat kids, particularly those primary infected at 3 week of age, showed milder clinical signs compared to animals from older groups. In agreement, animals subjected either to TW or EW did not display any significant reduced faecal consistency compatible to diarrhoea at the beginning of the experiment. By contrast, goat kids reared under AF had slightly high faecal score (around 2) at week 5 of age, which was most probably not attributed to Eimeria infections though, as OPG counts at this time were relatively low and significantly reduced when compared to the other two experimental groups. It has been documented that goat milk contains bioactive components that improve nutrient absorption, reduce the incidence of intestinal infection and balance the gut microflora in case of gastrointestinal disorder (Park, 2009). Conversely, milk replacers are mainly based on cow's milk powder with bigger fat globules, cereals and vegetable fats (Hernández-Castellano et al., 2015), which have digestive limitations in goat kids and may be the reason behind the diarrhoea.

It was unlikely that other microbial agents (bacteria or viruses, or protozoa of the Cryptosporidium genus) were a major contributor to diarrhoea throughout the experiment as there is no history of outbreaks by these other pathogens in this farm and these microbial infections are usually associated with earlier onset of clinical symptoms that was observed in this study kids (Molina et al., 1994). Giardia infections reported in this region are usually asymptomatic (Ruiz et al., 2008).

In arid and semi-arid regions, clinical coccidiosis is particularly evident between 6-8 weeks, sometimes coinciding with weaning, although the exact period could be affected by numerous factors including the degree of environmental contamination, the species involved, and even climatic factors (Ruiz et al., 2006). Accordingly, overall faecal oocyst counts found in the present study started to become significant from week 7 onwards. However, the comparative analysis between the three experimental groups determined some differences when comparing mean OPG values, which were particularly evident in AF group in relation to TW and EW groups. Furthermore, differences in the pattern of oocyst shedding were observed between the three management systems with peak oocyst shedding detected two weeks earlier for the TW group compared to EW or AF. Besides, around period where the maximum oocyst peak occurred, the highest faecal oocyst counts corresponded to AF group, with significant differences being recorded with respect to groups TW and EW. These high levels of OPG counts (almost 8 million OPG in some cases) could be explained by accumulation of infective oocysts in pens where goat kids artificially fed were reared, as discussed by Medrano-Galarza et al. (2018) for cattle in farms using automated milk feeders. Interestingly, the progressive contamination of the pens would have occurred despite initial counts where relatively low. In contrast to AF group, animals from groups TW and EW were housed in larger pens together with their dams. OPG counts of the mothers were not determined but, we could refer to previous data from the same area showing that faecal oocyst counts in dairy goats were relatively low (Ruiz et al., 2006), so it is expected that the environmental coccidian contamination of these pens was not too high. The increased susceptibility associated with early weaning stress could explain the higher OPG counts during the last weeks of the study observed in goat kids from group EW.

Thus, based on comparative OPG analysis among the three different management practices discussed above, TW would be the strategy in which the lowest oocyst counts were overall found. Differences were more evident when cumulative instead of week by week counts were considered. Actually, when compared to TW, EW and AF resulted in an increase of about $40 \%$ and more than $100 \%$ of the total amount of oocysts released up to the end of the experiment (week 15), respectively.
This estimation, although not technically accurate, could constitute an approximation to understand the average oocyst contamination of the environment in the different experimental groups, which has unquestionable epidemiological implications. For a more precise calculation of cumulative counts, daily rather than weekly counts should have been considered and the amount of faeces daily released by each animal examined (Ruiz et al., 2014).

Changes in OPG counts were associated to faecal scores, which is consistent with other studies that reported lower faecal consistency associated with multiplication of the parasite and subsequent damage to the intestinal mucosa (Ruiz et al., 2013a, b; Daugschies and Najdrowski, 2015). The relation between these two parameters was more evident in group EW, while peak values for faecal scores in group AF (highest score between weeks 7 and 8 of life) preceded the increased in faecal oocyst counts (weeks 8-10). This observation would indicate that damage of the intestinal mucosa and development of clinical sings already occurred before the oocyst excretion resulting from the gamogony started. Goat Eimeria species developing macroschizonts during merogony I in endothelial cells of the intestinal lymph vessels (such as E. ninakohlyakimovae, E. arloingi or E. christenseni) may cause severe injury of the gut mucosa and even develop a protective immune response during prepatency (Matos et al., 2017). Variations in the occurrence of these Eimeria species (having different prepatent periods) in the infected animals could explain why the negative association between these two parameters (OPG and FS) does not always coincide in time and, accordingly, no significant correlation could be demonstrated in any of the three management strategies.

In agreement to widely accepted evidence that Eimeria infections may affect growth performance (Daugschies and Najdrowski, 2005; Ruiz et al., 2013a; Matos et al., 2018), experimental groups that showed higher OPG counts throughout the study (AF and EW), had greater growth delay. However, as previously referred for FS, significant negative correlations between these two parameters could not be demonstrated synchronously over time. In contrast, the effects of high OPG levels on growth performance were observed in subsequent weeks, although correlations could only be demonstrated in TW group.

The high percentage of $E$. christenseni identified in the course of the study, which is considered of minor pathogenicity compared to E. ninakohlyakimovae and E. arloingi (Taylor and Catchpole, 1994), would explain that, despite high OPG counts reported in all groups, the presence of diarrhoea was not so evident and, indeed, watery diarrohea or bloody diarrhoea containing pieces of intestinal mucosa (score higher that 2) was barely observed. Actually, means OPG counts largely exceeded the value of $10^{5}$ OPG in most of the sampling times, which we could considered the threshold OPG value of clinical coccidiosis in goats in the Canary Islands.

The high prevalence of $E$. christenseni found in the study farm is in agreement with data recorded by our group in current field experiments on goat coccidiosis in the Canary Island, which contrasts with that published by Ruiz et al. (2006), who found E. christenseni as a minor Eimeria species in the same geographical environment. Further studies would be necessary to determine whether the increase in the prevalence of $E$. christenseni in these approximately 15 years is due to the continued use of anticoccidials such as diclazuril, which seem to have a greater effect on pathogenic Eimeria species, or to self-selection derived from the immune response (innate, acquired or passive immunity transmitted by colostrum), which would be more effective in highly immunogenic pathogenic species such as E. ninakohlyakimovae (Ruiz et al., 2013a).

As indicated in the results section, although the Eimeria species identified in the different experimental groups were the same, the oocyst shedding kinetics were different for each of the experimental group. However, no patterns were found for drawing definitive conclusions. As expected, an association between the decrease in faecal consistency and the increase in the percentages of species considered pathogenic (e. g. E. arloingi and E. ninakohlyakimovae) was recorded, although this temporal connection would have a time delay of at least 1 week. 
The increase in the percentages of $E$. arloingi and E. ninakohlyakimove observed three weeks after treatment with diclazuril both in groups TW and $\mathrm{AF}$ is in agreement to data showing that transient increases in relative percentages of $E$. christenseni after administration of either 1 or 2 $\mathrm{mg} / \mathrm{kg}$ body weight of diclazuril were soon exceeded by those of E. arloingi and E. ninakohlyakimovae from two weeks after treatment onwards (Ruiz et al., 2012). Compared to the previous two groups, E. christenseni was the most abundant species during the whole period examined after treatment in group EW. Whether the different profile of Eimeria species after treatment in goat kids from this group has some relation to the management of the weaning deserves further investigation.

Regardless of the differences among groups, it would be interested to note that relatively high oocyst counts were recorded during the two weeks after treatment. This is in disagreement to data published by Ruiz et al. (2012), who found OPG counts close to zero until two weeks posttreatment upon administration of diclazuril to naturally infected goat kids with Eimeria. The question arises of whether this finding could be an evidence of anticoccidial resistance, as the farm has a history of repeated treatment with diclazuril for almost 10 years. Further research to address this hypothesis need to be accomplished.

\subsection{Economic efficiency}

In the Canary Islands, the demand for goat milk for cheese production is expected to increase in the coming years (Fresno et al., 2014), so feeding milk to kids would be expensive if the current market prices are maintained or increased. Delgado-Pertíñez et al. (2009b) and Hassan et al. (2018) reported that natural rearing was around $30 \%$ more expensive than artificial rearing in Payoya and Shami goats, respectively. However, Paez Lama et al. (2013) found that total operating costs of Criollo kids raised on milk replacer were significantly higher than the costs of kids raised with goat milk. This is basically due to the low price of the goat milk in Argentina used in their calculations $(0.41 € / \mathrm{L})$. Moreover, these same authors estimated a reduction of $22 \%$ in the feeding costs whether the kids were weaned at 30 or 45 days of age. Thus, weaning at early stages would be beneficial in terms of economic profitability because of the highest marketable milk (Delgado-Pertíñez et al., 2009a).

On the other hand, it should be emphasized that about $89 \%$ of 400 cheese factories in Canary Islands are small farmhouses (Fresno et al., 2014), so is not easy to implement, from an economic perspective, an automated milk feeding system in the farm. Other option for the farmers would be the use of bucket feeders fitted with nipples, which are cheaper, but Bimczok et al. (2005) estimated that labor costs for bucket feeders were two to three times higher than for automated systems. Hence, artificial rearing gives rise to considerable misgivings for small goat keepers about additional labor costs and supplies associated with this management. Notwithstanding the above, Delgado-Pertínez et al. (2009a, b) explained that the situation might be very different for those families that produce and commercialize their own cheese through market channels, because goat milk acquires a much higher value than that paid to the producer who sells it to the dairy industry.

\section{Conclusion}

The application of artificial feeding system or weaning at 6 weeks in goat kids could improve the profitability of dairy goat farms by an increase in marketable milk yield in Canary Islands. However, animals reared under the traditional system exhibited the best growth performance and the lowest oocyst counts overall, despite the fact that this system involves much higher total feed costs. Therefore, farmers and veterinary technicians must consider the history of clinical coccidiosis and farm characteristics (production, size, kidding interval, health status, labor availability, etc.) in order to decide which rearing method best suits the productive, sanitary and economic needs.

\section{Aknowledgments}

This work was supported by grant CAIA2018-0002-00-00 from the Gobierno de Canarias. All authors have no conflict of interest and contributed to the content of this paper.

\section{Declaration of Competing Interest}

The authors report no declarations of Interest.

\section{References}

Abecia, L., Ramos-Morales, E., Martínez-Fernandez, G., Arco, A., Martín-García, A.I. Newbold, C.J., Yañez-Ruiz, D.R., 2014. Feeding management in early life influences microbial colonisation and fermentation in the rumen of newborn goat kids. Anim. Prod. Sci. 54, 1449-1454. https://doi.org/10.1071/AN14337.

Alyousif, M.S., Kasim, A.A., Al-Shawa, Y.R., 1992. Coccidia of the domestic goat (Capra hircus) in Saudi Arabia. Int. J. Parasitol. 22, 807-811. https://doi.org/10.1016/ 0020-7519(92)90131-90134.

Andrews, A.H., 2013. Some aspects of coccidiosis in sheep and goats. Small Rumin. Res. 110, 93-95. https://doi.org/10.1016/j.smallrumres.2012.11.011.

Argüello, A., Castro, N., Capote, J., 2004. Growth of milk replacer kids fed under three different managements. J. Appl. Anim. Res. 25, 37-40. https://doi.org/10.1080/ 09712119.2004.9706470.

Argüello, A., Castro, N., Capote, J., Solomon, M., 2005. Effects of diet and live weight at slaughter on kid meat quality. Meat Sci. 70, 173-179. https://doi.org/10.1016/j. meatsci.2004.12.009.

Balicka-Ramisz, A., Ramisz, A., Vovk, S., Snitynskyj, V., 2012. Prevalence of coccidia infection in goats in Western Pomerania (Poland) and West Ukraine region. Ann. Parasitol. 58, 167-171.

Bimczok, D., Röhl, F.W., Ganter, M., 2005. Evaluation of lamb performance and costs in motherless rearing of German Grey Heath sheep under field conditions using automatic feeding systems. Small Rumin. Res. 60, 255-265. https://doi.org/ 10.1016/j.smallrumres.2004.12.008.

BOC, 2019. Ayuda al productor de leche de caprino-ovino" del Programa Comunitario de Apoyo a las Producciones Agrarias de Canarias. http://www.gobiernodecanarias.or g/boc/2019/158/004.html (01/04/2020).

Castro, N., Argüello, A., Capote, J., 2017. The Canary Islands' Goat Breeds (Majorera, Tinerfeña, And Palmera): An Example of Adaptation to Harsh Conditions. Sustainable Goat Production in Adverse Environments: Volume II. Springer, Cham, pp. 221-231.

Cavalcante, A.C., Teixeira, M., Monteiro, J.P., Lopes, C.W., 2012. Eimeria species in dairy goats in Brazil. Vet. Parasitol. 183, 356-358. https://doi.org/10.1016/j. vetpar.2011.07.043.

Chartier, C., Paraud, C., 2012. Coccidiosis due to Eimeria in sheep and goats, a review. Small Rumin. Res. 103, 84-92. https://doi.org/10.1016/j.smallrumres.2011.10.022.

Costa, J.H.C., Meagher, R.K., Von Keyserlingk, M.A.G., Weary, D.M., 2015. Early pair housing increases solid feed intake and weight gains in dairy calves. J. Dairy Sci. 98, 6381-6386. https://doi.org/10.3168/jds.2015-9395.

Dai, Y.B., Liu, X.Y., Liu, M., Tao, J.P., 2006. Pathogenic effects of the coccidium Eimeria ninakohlyakimovae in goats. Vet. Res. Commun. 30, 149-160. https://doi.org/ 10.1007/s11259-006-3228-1.

Daugschies, A., Najdrowski, M., 2005. Eimeriosis in cattle: current understanding. J. Vet. Med. B 52, 417-427. https://doi.org/10.1111/j.1439-0450.2005.00894.x.

De Palo, P., Maggiolino, A., Centoducati, N., Tateo, A., 2015. Effects of different milk replacers on carcass traits, meat quality, meat color and fatty acids profile of dairy goat kids. Small Rumin. Res. 131, 6-11. https://doi.org/10.1016/j. smallrumres.2015.09.001.

De Paula Vieira, A., Von Keyserlingk, M.A.G., Weary, D.M., 2012. Presence of an older weaned companion influences feeding behavior and improves performance of dairy calves before and after weaning from milk. J. Dairy Sci. 95, 3218-3224. https://doi. org/10.3168/jds.2011-4821.

Delgado-Pertíñez, M., Guzmán-Guerrero, J.L., Mena, Y., Castel, J.M., GonzálezRedondo, P., Caravaca, F.P., 2009a. Influence of kid rearing systems on milk yield, kid growth and cost of Florida dairy goats. Small Rumin. Res. 81, 105-111. https:// doi.org/10.1016/j.smallrumres.2008.12.007.

Delgado-Pertínez, M., Guzmán-Guerrero, J.L., Caravaca, F.P., Castel, J.M., Ruiz, F.A., González-Redondo, P., Alcalde, M.J., 2009b. Effect of artificial vs. natural rearing on milk yield, kid growth and cost in Payoya autochthonous dairy goats. Small Rumin. Res. 84, 108-115. https://doi.org/10.1016/j.smallrumres.2009.06.014.

FEGA, 2020. Datos de las declaraciones obligatorias del sector lácteo ovino/caprino. Ministerio de Agricultura, Pesca y Alimentación. https://www.fega.es/sites/def ault/files/Fega_Decl_Lact_OviCapr_2020_01.pdf (01/04/2020).

Fresno, M., Álvarez, S., Diaz, E., Virto, M., de Renobales, M., 2014. Sensory profile of raw goat milk cheeses made with artisan kid rennet pastes from commercial-weight animals: alternative to farmhouse goat cheeses. J. Dairy Sci. 97, 6111-6115. https:// doi.org/10.3168/jds.2014-8238.

Fthenakis, G.C., Papadopoulos, E., 2018. Impact of parasitism in goat production. Small Rumin. Res. 163, 21-23. https://doi.org/10.1016/j.smallrumres.2017.04.001.

Gaddour, A., Najari, S., 2008. Adjustment of the kid's growth curve in pure goat breeds and crosses under southern Tunisian conditions. J. Appl. Anim. Res. 34, 117-120. https://doi.org/10.1080/09712119.2008.9706954. 
Ghiasi, H., Lupi, T.M., Mokhtari, M.S., 2018. The estimation of genetic parameters for growth curve traits in Raeini Cashmere goat described by Gompertz model. Small Rumin. Res. 165, 66-70. https://doi.org/10.1016/j.smallrumres.2018.06.015.

Gökdal, Ö., Özuğur, A.K., Atay, O., Eren, V., 2017. The effects of individual weaning based on birth weight on growth performance and milk yield in dairy goats. Turk. J. Vet. Anim. Sci. 41, 672-678. https://doi.org/10.3906/vet-1611-71.

Gregory, M.W., Catchpole, J., Nolan, A., Hebert, C.N., 1989. Ovine coccidiosis: studies on the pathogenicity of Eimeria ovinoidalis and E. crandallis in conventionally-reared lambs, including possible effects of passive immunity. Dtsch. Tierärztl. Wochenschr. 96, 287-292.

Hashemnia, M., Khodakaram-Tafti, A., Razavi, S.M., Nazifi, S., 2012. Experimental caprine coccidiosis caused by Eimeria arloingi: morphopathologic and electron microscopic studies. Vet. Res. Commun. 36, 47-55. https://doi.org/10.1007/ s11259-011-9511-9519.

Hassan, T.M.M., Abdelfattah, F.A., Kamel, M.S.A., 2018. Effect of milk replacer on kid pre-weaning growth, milk production and farm profitability of Shami goat. Egypt. J. Anim. Prod. 55, 43-50.

Hernández-Castellano, L.E., Moreno-Indias, I., Morales-delaNuez, A., Sánchez-Macías, D. Torres, A., Capote, J., Argüello, A., Castro, N., 2015. The effect of milk source on body weight and immune status of lambs. Livest. Sci. 175, 70-76. https://doi.org/ 10.1016/j.livsci.2015.02.011.

Hidalgo Argüello, M.R., Cordero del Campillo, M., 1999. Coccidiosis. In: Cordero del Campillo, M., Rojo Vázquez, F.A. (Eds.), Parasitología Veterinaria. McGraw-HillInteramericana de España, S.A.U., Madrid, Spain, pp. 195-212.

Keeton, S.T.N., Navarre, C.B., 2018. Coccidiosis in large and small ruminants. Vet. Clin. North Am. Food Anim. Practic. 34, 201-208. https://doi.org/10.1016/j. cvfa.2017.10.009.

Kume, K., Hajno, L., 2010. Study of growth curve variations for kids 0-6 months old of Alpine goat breed in Albania. Arch. Zootech. 13, 54.

Lambe, N.R., Navajas, E.A., Simm, G., Bunger, L., 2006. A genetic investigation of various growth models to describe growth of lambs of two contrasting breeds. J. Anim. Sci. 84, 2642-2654. https://doi.org/10.2527/jas.2006-041.

Levine, N.D., Ivens, V., 1986. The Coccidian Parasites (Protozoa, Apicomplexa) of Artiodactyla. University of Illinois Press, Urbana, pp. 120-141.

Lu, C.D., Potchoiba, M.J., 1988. Milk feeding and weaning of goat kids-a review. Small Rumin. Res. 1, 105-112. https://doi.org/10.1016/0921-4488(88)90025-90029.

Magistrelli, D., Aufy, A.A., Pinotti, L., Rosi, F., 2013. Analysis of weaning-induced stress in Saanen goat kids. J. Anim. Physiol. Anim. Nutr. 97, 732-739. https://doi.org/ 10.1111/j.1439-0396.2012.01315.x.

Matos, L., Muñoz, M.C., Molina, J.M., Rodríguez, F., Pérez, D., López, A.M., Ferrer, O., Hermosilla, C., Taubert, A., Ruiz, A., 2017. Protective immune responses during prepatency in goat kids experimentally infected with Eimeria ninakohlyakimovae. Vet. Parasitol. 242, 1-9. https://doi.org/10.1016/j.vetpar.2017.04.016.

Matos, L., Muñoz, M.C., Molina, J.M., Rodríguez, F., Pérez, D., López, A.M., Hermosilla, C., Taubert, A., Ruiz, A., 2018. Age-related immune response to experimental infection with Eimeria ninakohlyakimovae in goat kids. Res. Vet. Sci. 118, 155-163. https://doi.org/10.1016/j.rvsc.2018.02.004.

Medrano-Galarza, C., LeBlanc, S.J., Jones-Bitton, A., DeVries, T.J., Rushen, J., de Passillé, A.M., Endres, M.I., Haley, D.B., 2018. Associations between management practices and within-pen prevalence of calf diarrhea and respiratory disease on dairy farms using automated milk feeders. J. Dairy Sci. 101, 2293-2308. https://doi.org/ 10.3168/jds.2017-13733.

Molina, J.M., Rodríguez-Ponce, E., Ferrer, O., Gutiérrez, A.C., Hernández, S., 1994. Biopathological data of goat kids with cryptosporidiosis. Vet. Record. 135, 67-68.

Morales-delaNuez, A., Moreno-Indias, I., Sánchez-Macías, D., Capote, J., Juste, M.C., Castro, N., Hernández-Castellano, L.E., Argüello, A., 2011. Sodium dodecyl sulfate reduces bacterial contamination in goat colostrum without negative effects on immune passive transfer in goat kids. J. Dairy Sci. 94, 410-415. https://doi.org/ 10.3168/jds.2010-3624.
Najari, S., Gaddoun, A., Hamouda, M.B., Djemali, M., Khaldi, G., 2007. Growth model adjustment of local goat population under pastoral conditions in Tunisian arid zone. J. Agron. 6, 61-67.

Paez Lama, S., Egea, V., Grilli, D., Fucili, M., Allegretti, L., Guevara, J.C., 2013. Growth and economic performance of kid production under different rearing systems and slaughter ages in arid areas of Argentina. Small Rumin. Res. 110, 9-14. https://doi. org/10.1016/j.smallrumres.2012.08.005.

Panzuti, C., Mandrile, G., Duvaux-Ponter, C., Dessauge, F., 2018. Early weaning and high feeding level in post-weaning period did not impact milk production in Alpine dairy goats. J. Dairy Res. 85, 277-280. https://doi.org/10.1017/S0022029918000377.

Park, Y.W., 2009. Bioactive components in goat milk. Bioactive Components in Milk and Dairy Products. John Wiley \& Sons, p. 43.

Porter, T., Kebreab, E., Darmani Kuhi, H., López, S., Strathe, A.B., France, J., 2010. Flexible alternatives to the Gompertz equation for describing growth with age in turkey hens. Poultry Sci. 89, 371-378. https://doi.org/10.3382/ps.2009-00141.

Rocha, N.S., Vieira, R.A.M., Abreu, M.L.C., Araujo, R.P., Glória, L.S., Tamy, W.P., Nova, C.H., Fernandes, A.M., 2015. Traditional and biphasic nonlinear models to describe the growth of goat kids of specialized dairy breeds. Small Rumin. Res. 123, 35-46. https://doi.org/10.1016/j.smallrumres.2014.11.002.

Ruiz, A., González, J.F., Rodríguez, E., Martín, S., Hernández, Y.I., Almeida, R., Molina, J.M., 2006. Influence of climatic and management factors on Eimeria infections in goats from semi-arid zones. J. Vet. Med. B 53, 399-402. https://doi. org/10.1111/j.1439-0450.2006.00985.x.

Ruiz, A., Foronda, P., González, J.F., Guedes, A., Abreu-Acosta, N., Molina, J.M., Valladares, B., 2008. Occurrence and genotype characterization of Giardia duodenalis in goat kids from the Canary Islands, Spain. Vet. Parasitol. 154, 137-141. https:// doi.org/10.1016/j.vetpar.2008.03.003.

Ruiz, A., Matos, L., Muñoz, M.C., Hermosilla, C., Molina, J.M., Andrada, M., Rodríguez, F., Pérez, D., López, A., Guedes, A.C., Taubert, A., 2013a. Isolation of an Eimeria ninakohlyakimovae field strain (Canary Islands) and analysis of its infection characteristics in goat kids. Res. Vet. Sci. 94, 277-284. https://doi.org/10.1016/j. rvsc. 2012.08.003.

Ruiz, A., Muñoz, M.C., Molina, J.M., Hermosilla, C., Rodríguez, F., Andrada, M., Martín, S., Guedes, A., Pérez, D., Matos, L., López, A.M., Taubert, A., 2013b. Primary infection of goats with Eimeria ninakohlyakimovae does not provide protective immunity against high challenge infections. Small Rumin. Res. 113, 258-266. https://doi.org/10.1016/j.smallrumres.2013.01.006.

Ruiz, A., Muñoz, M.C., Molina, J.M., Hermosilla, C., Andrada, M., Lara, P., Bordón, E., Pérez, D., López, A.M., Matos, L., Guedes, A.C., Falcón, S., Falcón, Y., Martín, S., Taubert, A., 2014. Immunization with Eimeria ninakohlyakimovae-live attenuated oocysts protect goat kids from clinical coccidiosis. Vet. Parasitol. 199, 8-17. https:// doi.org/10.1016/j.vetpar.2013.09.032.

Soe, A.K., Pomroy, W.E., 1992. New species of Eimeria (Apicomplexa: Eimeriidae) from the domesticated goat Capra hircus in New Zealand. Syst. Parasitol. 23, 195-202. https://doi.org/10.1007/BF00010872.

Taylor, M.A., Catchpole, J., 1994. Review article: coccidiosis of domestic ruminants. Appl. Parasitol. 35, 73-86.

Thienpont, D., Rochette, F., Van Parijs, O.F.J., 1979. Diagnosing Helminthiasis by Coprological Examination. Janssen Research Foundation, Beerse, p. 187.

Tsiplakou, E., Papadomichelakis, G., Sparaggis, D., Sotirakoglou, K., Georgiadou, M., Zervas, G., 2016. The effect of maternal or artificial milk, age and sex on three muscles fatty acid profile of Damascus breed goat kids. Livest. Sci. 188, 142-152. https://doi.org/10.1016/j.livsci.2016.04.014.

Windsor, P.A., Nampanya, S., Putthana, V., Keonam, K., Johnson, K., Bush, R.D., Khounsy, S., 2018. The endoparasitism challenge in developing countries as goat raising develops from smallholder to commercial production systems: A study from Laos. Vet. Parasitol. 251, 95-100. https://doi.org/10.1016/j.vetpar.2017.12.025.

Zhao, G.H., Lei, L.H., Shang, C.C., Gao, M., Zhao, Y.Q., Chen, C.X., Chen, D.K., 2012. High prevalence of Eimeria infection in dairy goats in Shaanxi province, northwestern China. Trop. Anim. Health Prod. 44, 943-946. https://doi.org/ 10.1007/s11250-011-9997-9998. 